\title{
A Simulated Preconditioning of Typhoon Genesis Controlled by a Boreal Summer Madden-Julian Oscillation Event in a Global Cloud-system-resolving Model
}

\author{
Kazuyoshi Oouchi ${ }^{1}$, Akira T. Noda ${ }^{1}$, Masaki Satoh ${ }^{2}$, Hiroaki Miura ${ }^{1,3}$, Hirofumi Tomita ${ }^{1}$, \\ Tomoe Nasuno ${ }^{1}$ and Shin-ichi Iga ${ }^{1}$ \\ ${ }^{1}$ Frontier Research Center for Global Change, JAMSTEC, Yokohama, Japan \\ ${ }^{2}$ Center for Climate System Research, The University of Tokyo, Kashiwa, Japan \\ ${ }^{3}$ Colorado State University, Fort Collins, Colorado, USA
}

\begin{abstract}
A preconditioning of a typhoon genesis over the North Western Pacific by an Madden-Julian Oscillation (MJO) event is simulated in a boreal summer numerical experiment conducted using a global cloud-systemresolving model. The simulation highlights the importance of the following processes in the typhoon genesis that were not clearly captured in the conventional general circulation models: as the MJO propagates over that region, the easterly shear (with an enhanced lowlevel westerly) of the western branch of the MJO's circulation moderates the climatological westerly shear that is otherwise persistent and inhibits cyclogenesis there. Meanwhile, its attendant cyclonic vorticity from the westerly region migrates northward, causing the genesis to occur. The trough in the upper troposphere at $15^{\circ}-20^{\circ} \mathrm{N}$ is found to contribute to the genesis. The result demonstrates the performance of a global cloudsystem-resolving model at predicting tropical cyclogenesis associated with the MJO in the North Western Pacific during the active typhoon season in boreal summer.
\end{abstract}

\section{Introduction}

Improving the prediction of tropical cyclogenesis has broad socioeconomic impacts. The need for improvement has been high in the weather forecasting field and will be higher in the future, greenhousewarmed climate condition, when tropical cyclones are projected to become more intense (IPCC 2007) and destructive. Our current understanding of the genesis process remains fragmentary despite the expanded observational network in the tropics after a seminal article (Yanai 1964) on the issue. It was in the past few decades that observational studies suggested a possible link between the MJO, a planetary-scale and quasi-periodic tropical weather event, and statistics of tropical cyclogenesis over some oceanic basins, including the North Western Pacific (Nakazawa 1986).

In terms of the modeling approach, both the MJO (Lin et al. 2006) and tropical cyclogenesis are elusive factors. Clouds drive both phenomena, and difficulty in handling a cloud spanning less than the grid spacing of a given model has always hampered our understanding of the phenomena. Atmospheric general circulation models (GCMs) typically use a grid spacing of O (100 $\mathrm{km}$ ) or so to cover the globe, and the simulated cloud disturbances are too fuzzy to pick up anything as small as a tropical cyclone in the genesis stage and the clouds embedded in an MJO. A way to avoid this difficulty is

Corresponding author: Kazuyoshi Oouchi, Frontier Research Center for Global Change, Japan Agency for Marine-Earth Science and Technology, 3173-25 Showa-machi, Kanazawa-ku, Yokohama 236-0001, Japan. E-mail: k-ouchi@jamstec.go.jp. (c)2009, the Meteorological Society of Japan. cumulus convection parameterisation, which was typically subject to uncertainties when implemented in conventional GCMs. The most compelling difficulty is its inability to represent mechanisms associated with mesoscale convection, a key convective element of $\mathrm{O}(10 \mathrm{~km})$ scale in tropical cyclones (Yamasaki 1986, 2006) and the MJO (Oouchi and Yamasaki 2001).

Alternatively, a "global" cloud-system-resolving model (GCSRM) was suggested. The advent of the Earth Simulator facilitated this computationally intensive calculation. The Nonhydrostatic ICosahedral Atmospheric Model (NICAM) (Satoh et al. 2008; Tomita and Satoh 2004 ) is a prototype GCSRM targeted for the comprehensive understanding of tropical phenomena, including the problem described above. In a boreal winter case study using NICAM, a typical MJO event and an associated tropical cyclone development off the northwest coast of Australia were successfully simulated (Miura et al. 2007). In this paper, we highlight a case of a MJOassociated preconditioning of tropical cyclogenesis in the North Western Pacific, in the boreal summer (2004) - another challenging area and season that climate models generally have difficulty simulating well.

\section{Method}

The basic configuration of NICAM and the implemented physical schemes are described in Satoh et al. (2008), and Tomita and Satoh (2004). The grid spacing used in the experiment is $7 \mathrm{~km}$ or $14 \mathrm{~km}$. When the results from two types of spacing were compared, the main conclusion of this paper was not affected. Our report is based on a dataset from the $14-\mathrm{km}$ mesh experiment, which is easier to handle. The $14-\mathrm{km}$ mesh is expected to be fine enough to resolve cloud clusters that are ubiquitous in the tropics and general features of mesoscale organised convection that constitute the essential element of a tropical cyclone, such as eyewall clouds and spiral rainbands. No cumulus parameterization is used in the experiment. Arguably, we need to implement a parameterisation of cumulus convection in such a grid spacing to accurately handle mesoscale organized forms of cumulus convection. If more emphasis is placed on the analysis of mesoscale convective features (Yamasaki 2006), the implementation is likely to be significant. We used a cloud microphysics scheme (Grabowski 1998) that treats two classes of solid phases consisting of cloud ice and snow. Major improvements in the physical schemes from the previous version of the model (Miura et al. 2007) include an upgraded version of the turbulent boundary layer scheme (Nakanishi and Niino 2004), in which the thermodynamical effects of the subgrid scale condensation were incorporated (Noda et al. 2008).

The time integration was performed from 1 June to 10 Nov., 2004, using the initial atmospheric conditions interpolated from the National Centres for Environmental Prediction (NCEP) Global Tropospheric Analyses at 0000 UTC on 1 June, 2004. The year was selected in 
this experiment for the following reasons. First, it is the year marked by enhanced activity of tropical cyclones (Nakazawa 2006). For instance, as many as 10 tropical cyclones made landfall in Japan. Second, the year is marked by clear signals of an MJO propagation in the boreal summer. The sea surface temperature was provided by a weekly interpolated National Organisation of Atmospheric Agency (NOAA)-Objectively Interpolated (OI) sea surface temperature. In the analyses presented in this letter, we also used the following observational datasets: the Tropical Rainfall Measuring Mission (TRMM) 3B42 dataset for precipitation, and the NCEPNational Centre for Atmospheric Research (NCAR) reanalysis dataset for other dynamical fields. No nudging techniques were applied in the time integration; therefore the genesis of clouds and convections and their interactions with atmospheric disturbances were expressed as internally driven, spontaneous processes in the global cloud-system-resolving model (GCSRM).

This letter focuses on a case of a preconditioning of typhoon genesis in the North Western Pacific in June, which was simulated in the boreal summer GCSRM experiment. Details of the simulated MJO and the associated typhoon genesis in the entire period (June to October) will be reported elsewhere.

\section{Results}

Figure 1 compares a monthly mean climatology of the precipitation (purple lines), zonal velocity (colour shades), and velocity (arrows) at $850 \mathrm{hPa}$ for the period June 2004 between the NICAM run and the observation from the National Centres for Environmental Prediction /National Centre for Atmospheric Research reanalysis (velocity) or the Tropical Rainfall Measuring Mission 3B42 dataset (precipitation). The simulated velocity fields are generally consistent with the observation in terms of the elongated area of westerly or southwesterly winds further to the northeast. The westerly wind tongue off the south coast of Japan is simulated as well. Yet the eastern edge of the westerly wind region in the tropics is situated 30-40 degree westward than that in the observation, and the westerly region is simulated more equator-ward than in the observation. These discrepancies are the subject of ongoing investigation.

For the precipitation field, the simulated pattern is basically consistent with the observation, except for the excessive bias over the tropical Indian Ocean $\left(60-90^{\circ} \mathrm{E}\right.$, $\left.10^{\circ} \mathrm{S}-10^{\circ} \mathrm{N}\right)$. Apart from this, it is noteworthy that the simulated horizontal pattern of precipitation generally captures the observed one in the equatorial western Pacific $\left(120-160^{\circ} \mathrm{E}, 0-20^{\circ} \mathrm{N}\right)$. Patterns and evolution of clouds and associated synoptic-scale systems in the tropics and sub-tropics are also represented in unprecedented details.

Figure 2 shows Hovmoller plots of zonal velocity at $200 \mathrm{hPa}$, which is a deviation from the zonal mean, processed with a 4-day running mean. A pronounced eastward-propagating signal is simulated, and the signal shares many features with the observed MJO (Madden and Julian 1971, 1972). The synoptic-scale propagating signals are embedded in the planetary-scale structure and demonstrate the typical multi-scale characteristics of an MJO event, as exemplified in the boreal winter MJO simulation as well (Miura et al. 2007). The running mean used in creating Fig. 2 renders the synoptic- and planetary- scale signatures more easily detectable. On the other hand, this may obscure the smaller-scale, fastpropagating (at the speed of about $40 \mathrm{~m} \mathrm{~s}^{-1}$ ) signals frequently observed with an MJO (Milliff and Madden 1996). NICAM also simulated these types of signals (not shown)

To illustrate the relationship between the MJO propagation and a case of tropical cyclogenesis, Fig. 3 presents time-meridional plots of precipitation, zonal wind anomaly at $850 \mathrm{hPa}$, and relative vorticity at 850

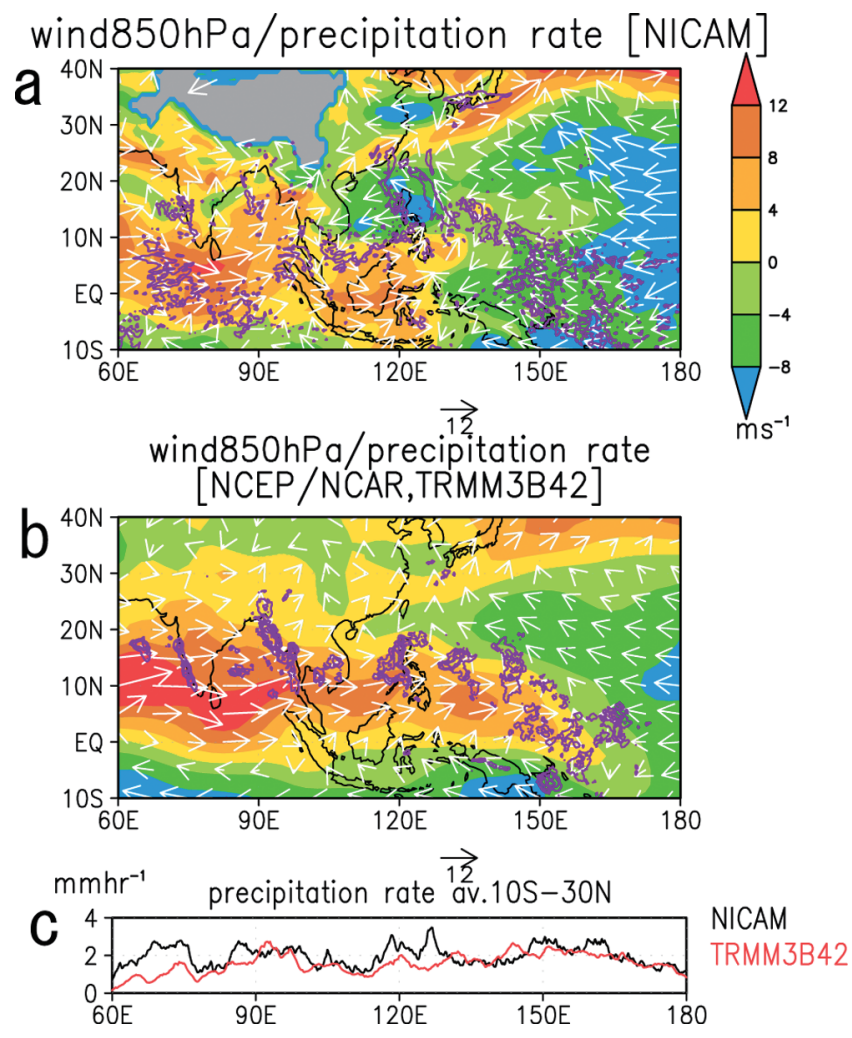

Fig. 1. Model versus observed $850 \mathrm{hPa}$ horizontal velocity (shaded) and precipitation rate (purple lines; more than $0.9 \mathrm{~mm}$ $\mathrm{hr}^{-1}$ ) one-month averaged for June 2004. (a) NICAM, (b) observed. (c) precipitation rate averaged over $10^{\circ} \mathrm{S}-30^{\circ} \mathrm{N}$ for simulation (black line) and observation from TRMM_3B42 (red line).

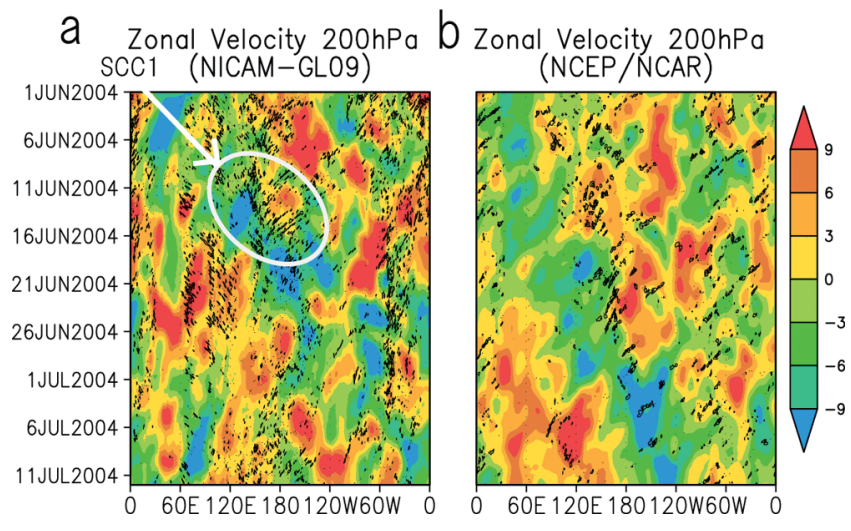

Fig. 2. Near-equatorial $200 \mathrm{hPa}$ zonal velocity $\left(\mathrm{m} \mathrm{s}^{-1}\right)$ and precipitation rate (black lines). Plots display averaged values over $2^{\circ} \mathrm{S}-8^{\circ} \mathrm{N}$, for the period from 1 June to 11 July 2004 for (a) NICAM, (b) observation from NCEP-NCAR Reanalysis. Plots are smoothed with a 4-day running mean. The observed precipitation in (b) is from TRMM_3B42.

and $200 \mathrm{hPa}$. A prominent feature is the quasi-periodic enhancement of the low-level westerly anomaly in the equatorial region (c), northward migration of cyclonic vorticity (b), and concomitant organisation and movement of the precipitation area (a). We focus on the migration of cyclonic vorticity and precipitation areas simulated during the period of 16-28 June.

Several precipitation clusters in the equatorial regions in the $1-13$ June period corresponds to super cloud clusters (SCCs) (Nakazawa 1988; Hayashi and 


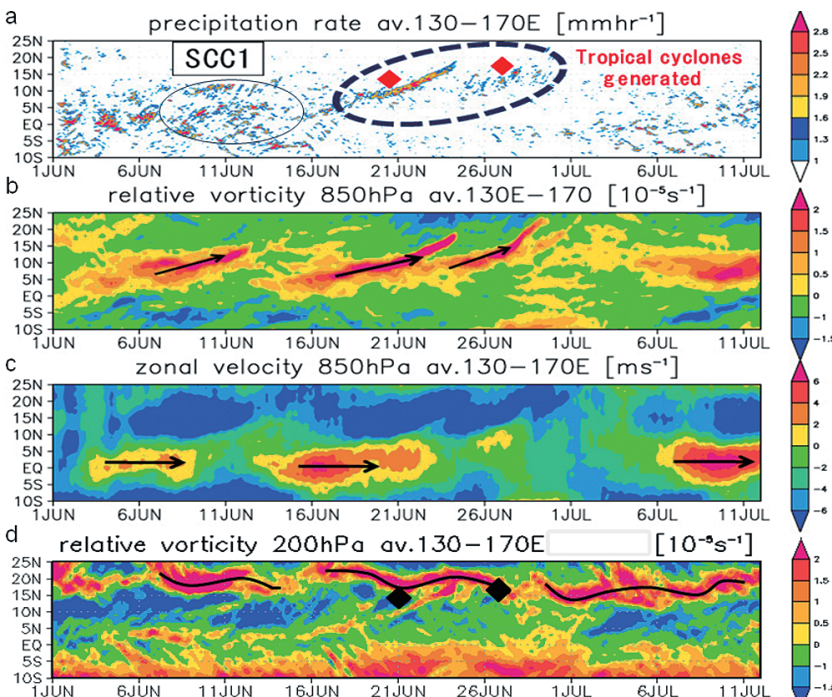

Fig. 3. Time-meridional section for (a) zonally averaged (130$170^{\circ} \mathrm{E}$ ) precipitation rate, (b) $850 \mathrm{hPa}$ relative vorticity, (c) 850 $\mathrm{hPa}$ zonal velocity anomaly from zonal average over all longitudinal belts, and (d) $200 \mathrm{hPa}$ relative vorticity. Red diamonds in the upper panel correspond to the timings and locations of the generated tropical cyclones.

Sumi 1986) and other transient convection events. SCC exhibits a marked hierarchy of convection as observed. The anomalous westerly starting approximately on 13 June was induced by the activity of SCC. The westerly persists beyond one week up to approximately 23 June. The northward migration of a cyclonic vorticity starts approximately on 16-18 June and continues until approximately 24 June (b). In addition, the accompanying migration of the precipitation area approximately on 18-24 June is noteworthy and corresponds to a tropical cyclone in its formative stage. The enhancement of the low-level anomalous westerly (as shown in Fig. 3) is a key for the cyclogenesis, consistent with the observations (Lau et al. 1989; Chen et al. 1996). Panel (d) indicates that the genesis marked by the black diamond is likely to be prompted by the trough (cyclonic vorticity; black lines) at $200 \mathrm{hPa}$ that is present quasi-persistently in $15-20^{\circ} \mathrm{N}$.

To check a change in the velocity field associated with the MJO propagation, Fig. 4 displays daily snapshots of the vertical shear of zonal velocity (U200-U850; $>0$ for westerly shear, < 0 for easterly shear, colour shade), and precipitation (superimposed black lines) covering the period of 16-27 June, when a low-level westerly anomaly developed and persisted in association with an MJO (see Fig. 2). The line plot in each subpanel shows the zonal velocity anomaly at $850 \mathrm{hPa}$ averaged over $5^{\circ} \mathrm{S}-10^{\circ} \mathrm{N}$. A precipitation area of a spiral form, indicative of a tropical cyclone, becomes discernible at approximately $150^{\circ} \mathrm{E}, 8^{-1} 10^{\circ} \mathrm{N}$ on 19 June. Three or four days before the formation (from 17 June), the equatorial region undergoes an easterly shear (low-level westerly) exceeding $8 \mathrm{~m} \mathrm{~s}^{-1}$, influenced primarily by an MJO's anomalous low-level westerly (see Fig. 2). In the next two days (18-19 June), the shear gradually weakens and a tropical cyclone develops on 19 June. The tropical cyclone moves north-westward afterwards and reaches approximately $135^{\circ} \mathrm{E}, 18^{\circ} \mathrm{N}$ off the Philippine Island on 24 June. Another tropical cyclone subsequently developed near the boundary of the easterly shear (low-level westerly) and westerly shear (low-level easterly) at approximately $140^{\circ} \mathrm{E}, 10^{\circ} \mathrm{N}$ on 26 June. This may be developed by the low-level horizontal cyclonic shear, and the mechanism of cyclogenesis may be different from the previous one.
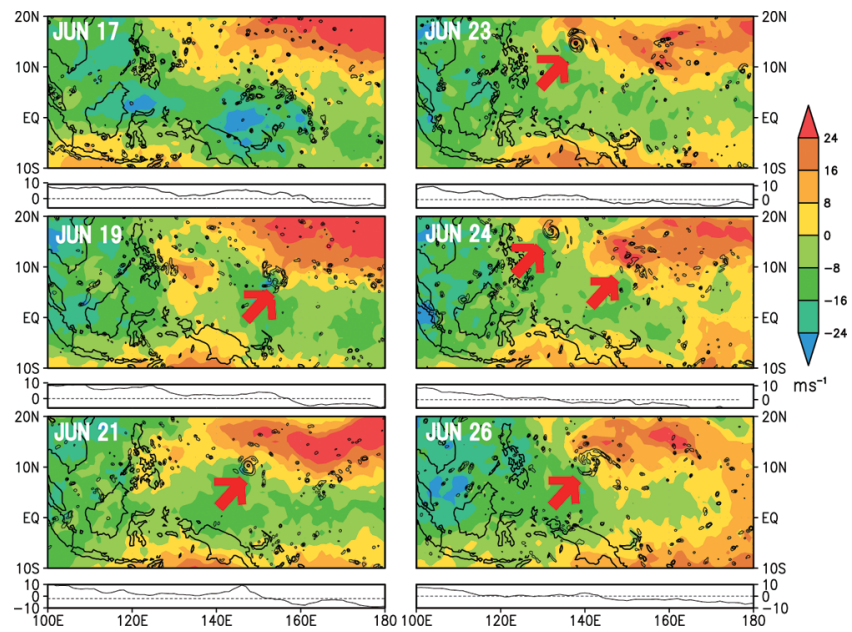

Fig. 4. Daily snapshots of vertical shear for zonal velocity as a difference between $200 \mathrm{hPa}$ minus $850 \mathrm{hPa}$ (colour shades), precipitation (black lines), and $850 \mathrm{hPa}$ zonal velocity averaged over $5^{\circ} \mathrm{S}-8^{\circ} \mathrm{N}$ (line in each subpanel) for $17,19,21,23,24,26$ June in 2004 . The tropical cyclone is marked by red arrow.

It is instructive to know if the simulated tropical cyclone has an observed counterpart. Figure 5 compares the tropical cyclone tracks. The storm is intensified with the accompanying spiral band becoming discernible at approximately $138^{\circ} \mathrm{E}, 12^{\circ} \mathrm{N}$ on 26 June (see Fig. 4). The simulated track resembles the observed counterpart (TC0407), especially in terms of the north-westward movement and timing of intensification (the red line indicates the maximum surface velocity exceeding $64 \mathrm{kt}$ ). As the case is simulated more than two weeks after the time integration starts, the indicated similarity is encouraging.

\section{Concluding remarks}

We have reported a success at simulating a typhoon genesis in the North Western Pacific in a boreal summer period using the GCSRM, NICAM. Highlighted here is a preconditioning for the genesis associated with the initial cycle of the MJO's propagation, in agreement with the observations (Nakazawa 2006; Fu et al. 2007), in addition to a presence of quasi-persistent cyclonic disturbance in the upper troposphere that is favorable for the genesis. The cycle of MJO is reproduced reasonably for the first time using GCSRM, and the case presented here demonstrates a promising potential of GCSRM in predicting the tropical cyclogenesis associated with MJO. It is encouraging that the GCSRM at $14-\mathrm{km}$ mesh captures a tropical cyclogenesis as a result of spontaneous interaction among convection and disturbances approximately 20 days after the start of integration. Another simulation at $7-\mathrm{km}$ mesh was also conducted, and from a preliminary analysis, we confirmed that the suggested link between an MJO and tropical cyclogenesis remains robust, consistently with the $14-\mathrm{km}$ mesh simulation.

It is of note that the other MJO simulation using NICAM (Miura et al. 2007) also captured realistic tropical cyclogeneses in the Southern Hemisphere in boreal winter period, and convective features in the cyclones (Fudeyasu et al. 2008). Compared to the conventional climate models, GCSRM has impressive strength at representing tropical convection and the convectively coupled disturbances; even a sophisticated, $20-\mathrm{km}$ mesh climate model generally failed to simulate the formation of western Pacific tropical cyclone and MJO of enough strength, and the failure was inferred to come from uncertainty in a cumulus parameterization 


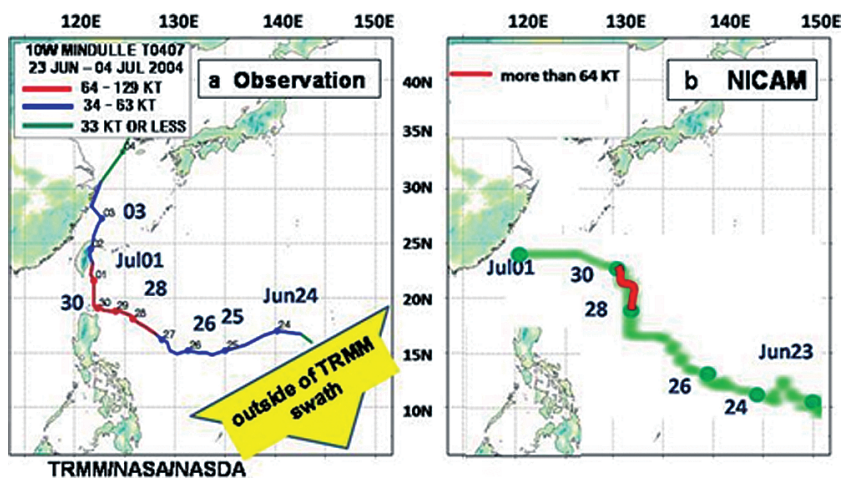

Fig. 5. (a) Observed TC0407 track, (b) NICAM simulated track. Simulated track for a maximum surface velocity exceeding 64 knots is in red, and that for not exceeding is in green. Observed track and plotting framework is provided by Tropical Cyclone Database maintained by Japan Aerospace Exploration Agency (JAXA)/Earth Observation Research Center (EORC)

(Oouchi et al. 2006). The implication from the present results is therefore consistent with the "cloud-resolving" spirit pointing to the importance of the direct treatment of mesoscale convection (Yamasaki 1986) in the model, as articulated in the development policy of NICAM (Satoh et al. 2008).

Our study does not address some key issues, such as the influence of easterly waves (Yanai 1964; Fu et al. 2007), and monsoon trough (Yasunari 1979; Nakazawa 2006) on tropical cyclogenesis. Even if an MJO provides large-scale environmental control on tropical cyclogenesis, the combination of these factors can be important, which is under investigation using the GCSRM framework.

\section{Acknowledgments}

The numerical calculations were conducted on the Earth Simulator/JAMSTEC, under the framework of the Innovative Program of Climate Change Projection for the $21^{\text {st }}$ century (KAKUSHIN) project "Global Cloud Resolving Model Simulations toward More Accurate and Sophisticated Climate Prediction of Cloud/precipitation Systems" funded by Ministry of Education, Culture, Sports, Science and Technology (MEXT). We thank T. Matsuno, M. Yamasaki, T. Nakazawa, Y. Wang, K. Hamilton, and B. Fu for discussion and advice. We acknowledge Program Director, A. Noda for logistical support and valuable comments on the earlier version of the manuscript. The comments from the reviewers helped improve the presentation.

\section{References}

Chen, S. S., R. A. Houze Jr., and B. E. Mapes, 1996: Multiscale variability of deep convection in relation to large-scale circulation in TOGA COARE. J. Atmos. Sci., 53, 13801409.

Fu, B., T. Li, M. Peng, and F. Weng, 2007: Analysis of tropical cyclone genesis in the western North Pacific for 2000 and 2001. Weather Forecasting, 22, 763-780.

Fudeyasu, H., Y. Wang, M. Satoh, T. Nasuno, H. Miura, and W. Yanase, 2008: The global cloud-system-resolving model NICAM successfully simulated the lifecycles of two real tropical cyclones. Geophys. Research Lett., 35, L22808, doi:10.1029/2008GL0360033.

Grabowski, W. W., 1998: Toward cloud resolving modeling of large-scale tropical circulation: A simple cloud microphysics parameterization. J. Atmos. Sci., 55, 3283-3298.

Hayashi, Y.-Y., and A. Sumi, 1986: The 30-40 day oscillations simulated in an "aqua planet" model. J. Meteor. Soc. Japan, 64, 451-467.
IPCC (Intergovernmental Panel on Climate Change), 2007: Climate Change 2007: The physical science basis Contribution of Working Group I to the Fourth Assessment Report of the Intergovernmental Panel on Climate Change. Chapter 8 Climate models and their evaluation, 625 pp. (Eds. Solomon, S. et al.), Cambridge Univ. Press, Cambridge.

Lau, K. M., L. Peng, C. H. Sui, and T. Nakazawa, 1989: Dynamics of super cloud clusters, westerly wind bursts, 30-60 day oscillation and ENSO: an unified view. J. Meteor. Soc. Japan, 67, 205-219.

Lin, J.-L., G. N. Kiladis, B. E. Mapes, K. M. Weickmann, K. R. Sperber, W. Lin, M. C. Wheeler, S. D. Shubert, A. Del Genio, L. J. Donner, S. Emori, J.-F. Gueremy, F. Hourdin, P. J. Rasch, E. Roeckner, and J. F. Scinocca, 2006: Tropical intraseasonal variability in 14 IPCC AR4 climate models. Part I: Convective Signals. J. Climate, 19, 2665-2690.

Madden, R. A., and P. R. Julian, 1971: Detection of a 40-50 day oscillation in the zonal wind in the tropical Pacific. $J$. Atmos. Sci., 28, 702-708.

Madden, R. A., and P. R. Julian, 1972: Description of globalscale circulation cells in the tropics with a 40-50 day period. J. Atmos. Sci., 29, 1109-1123.

Milliff, R. F., and R. A. Madden, 1996: The existence and vertical structure of fast, eastward-moving disturbances in the equatorial troposphere. J. Atmos. Sci., 53, 586-597.

Miura, H., M. Satoh, T. Nasuno, A. T. Noda, and K. Oouchi, 2007: A Madden-Julian Oscillation event simulated using a global cloud-resolving model. Science, 318, 1763-1765.

Nakanishi, M., and H. Niino, 2004: An improved Mellor-Yamada level-3 model: Its numerical stability and application to a prediction of advection fog. Bound.-Layer Meteor., 119, 397-407, doi:10.1007/s10546-005-9030-8.

Nakazawa, T., 1986: Mean features of 30-60 day variations as inferred from 8-year OLR data. J. Meteor. Soc. Japan, 64, 777-786.

Nakazawa, T., 1988: Tropical super clusters within intraseasonal variations over the western Pacific. J. Meteor. Soc. Japan, 66, 823-839.

Nakazawa, T., 2006: Madden-Julian Oscillation activity and typhoon landfall on Japan in 2004. SOLA, 2, 136-139, doi: 10.2151 /sola.2006.035.

Nasuno, T., H. Tomita, S. Iga, H. Miura, and M. Satoh, 2007: Multiscale organization of convection simulated with explicit cloud processes on an aquaplanet. J. Atmos. Sci., 64, 1902-1921.

Noda, A. T., K. Oouchi, M. Satoh, H. Tomita, T. Nasuno, S. Iga, and H. Miura, 2008: Characteristics of the boundary-layer clouds in a global $14 \mathrm{~km}$-mesh experiment by NICAM. The 15th International Conference on Clouds and Precipitation, 7-11 July 2008, Cancun, Mexico, International Association of Meteorology and Atmospheric Sciences (8.4 in cdrom).

Oouchi, K., and M. Yamasaki, 2001: An MJO-like gravity wave and superclusters simulated in a two-dimensional cumulus-scale-resolving model under a warm pool condition. $J$. Meteor. Soc. Japan, 79, 201-218.

Oouchi, K., J. Yoshimura, H. Yoshimura, R. Mizuta, S. Kusunoki, and A. Noda, 2006: Tropical cyclone climatology in a global-warming climate as simulated in a $20 \mathrm{~km}$-mesh global atmospheric model: Frequency and wind intensity analyses. J. Meteor. Soc. Japan, 84, 259-276.

Satoh, M., T. Matsuno, H. Tomita, H. Miura, T. Nasuno, and S. Iga, 2008: Nonhydrostatic Icosahedral Atmospheric Model (NICAM) for global cloud-resolving simulations. $J$. Comput. Phys., 227, 3486-3514.

Tomita, H., and M. Satoh, 2004: A new dynamical framework of nonhydrostatic global model using the icosahedral grid. Fluid Dyn. Res., 34, 357-400.

Yamasaki, M., 1986: A three-dimensional tropical cyclone model with parameterized cumulus convection. Pap. Meteor. Geophys., 37, 205-234.

Yamasaki, M., 2006: A numerical study of tropical cyclone formation from two mesoscale convective systems in a largescale convective system. SOLA, 2, 57-60, doi:10.2151/ sola.2006.003.

Yanai, M., 1964: Formation of tropical cyclones. Reviews of Geophysics, 2, 367-414.

Yasunari, T., 1979: Cloudiness fluctuations associated with the northern hemisphere summer monsoon. J. Metor. Soc. Japan, 57, 227-242.

Manuscript received 24 October 2008, accepted 7 April 2009

SOLA: http://www.jstage.jst.go.jp/browse/sola/ 